The University of San Francisco

USF Scholarship: a digital repository @ Gleeson Library |

Geschke Center

Philosophy

College of Arts and Sciences

$12-2003$

\title{
Defending Conventions as Functionally A Priori Knowledge
}

David J. Stump

University of San Francisco, stumpd@usfca.edu

Follow this and additional works at: http://repository.usfca.edu/phil

Part of the Philosophy Commons

\section{Recommended Citation}

Stump, David J., "Defending Conventions as Functionally A Priori Knowledge" (2003). Philosophy. Paper 9.

http://repository.usfca.edu/phil/9

This Article is brought to you for free and open access by the College of Arts and Sciences at USF Scholarship: a digital repository @ Gleeson Library | Geschke Center. It has been accepted for inclusion in Philosophy by an authorized administrator of USF Scholarship: a digital repository @ Gleeson

Library | Geschke Center. For more information, please contact repository@usfca.edu. 


\title{
Defending Conventions as Functionally a Priori Knowledge
}

\author{
David J. Stump ${ }^{\dagger}$
}

Recent defenses of a priori knowledge can be applied to the idea of conventions in science in order to indicate one important sense in which conventionalism is correct-some elements of physical theory have a unique epistemological status as a functionally a priori part of our physical theory. I will argue that the former a priori should be treated as empirical in a very abstract sense, but still conventional. Though actually coming closer to the Quinean position than recent defenses of a priori knowledge, the picture of science developed here is very different from that developed in Quinean holism in that categories of knowledge can be differentiated.

It would be hard to find a more crucial epistemological problem than that of the character of a priori knowledge.

Our "empirical propositions" do not form a homogeneous mass.

1. Introduction. One way to organize much of twentieth-century philosophy of science is to read it as a series of debates over what had been considered a priori knowledge. Although synthetic a priori knowledge was officially rejected by the Vienna Circle with their adoption of empiricism in the 1929 pamphlet "Wissenschaftliche Weltauffassung: Der Wiener Kreis" (Neurath [1929] 1974), parts of knowledge that had been considered a priori by Kant, such as geometry, space and time, causality, and the basic principles of physics, were widely discussed throughout the twentieth century and statements about them have often been given a special role, either as conventions, or as the hard core of scientific theories. One would

$†$ To contact the author, please write to: University of San Francisco, Philosophy Department, 2130 Fulton Street, San Francisco, CA 94117; e-mail: stumpd@usfca.edu.

Philosophy of Science, 70 (December 2003) pp. 1149-1160. 0031-8248/2003/7005-0024\$10.00

Copyright 2003 by the Philosophy of Science Association. All rights reserved. 
think that Quine's critique of the analytic-synthetic distinction (1953) would have put the final nail in the coffin of a priori knowledge and that a holism in which all scientific statements are justified empirically has replaced the notion of any special status for what was formerly considered to be a priori. However, several recent discussions have questioned to what extent a priori knowledge has been refuted (Creath 1991; Friedman 2001; Hanson and Hunter 1992; Stein 1992; Richardson 1997). While it is possible to defend Carnap or even Kant from Quinean holistic empiricism, I will take a new approach to the question and argue that the former a priori should be treated as empirical in a very abstract sense but also as conventional. By conventionalism, I mean the idea that some elements of physical theory have a unique epistemological status - one must adopt these elements in order to begin empirical inquiry. They therefore function as an a priori part of our physical theory that is chosen for conceptual or pragmatic reasons, prior to any empirical testing. Though I am willing to concede to Quine that these conventions are ultimately empirical, the picture of knowledge developed here is very different from that developed in Quinean holism in that categories of knowledge can be differentiated. While Quine admits that some elements of empirical theory are much less likely to be revised than others, he underestimates the asymmetric relation between the "hard core" and the "periphery." It is not just that the periphery is more likely to be revised than the hard core, but rather that the statements of the periphery cannot even be stated, let alone tested, without the hard core functioning as an a priori in the Kantian sense as a necessary precondition.

The literature on conventions in science begins with Mach and Poincaré (who hold that we choose Euclidean geometry to describe space, regardless of what experiment says) and continues with the Vienna Circle, especially Schlick, Carnap, and Reichenbach (in his trilogy of books on spacetime). A different interpretation of conventionalism was later developed by C. I. Lewis, Victor Lenzen, Arthur Pap, who is responsible for the term "functional a priori," and by Russell Norwood Hanson. Kuhn eventually (and tentatively) picked up the idea of a conventional treatment of synthetic a priori knowledge as an explication of his own views (Kuhn 1990), and Ian Hacking has advocated something similar to conventionalism with his notion of "styles of reasoning" (Hacking 1992). Many of these treatments of a priori knowledge share the idea that what Kant took to be necessary can and indeed has changed through the development of scientific theories. ${ }^{1}$

1. Lakatos criticized Poincaré for seeing conventions (especially Euclidean geometry) as unchanging (Lakatos [1970] 1978, 49). While it is true that Poincaré said there would never be a reason to stop using Euclidean geometry in physical theory, he was also willing to 
The development of non-Euclidean geometries, and especially of the General Theory of Relativity (GTR), made a profound impact on philosophy of science in the early twentieth century by showing philosophers that fundamental aspects of physical theory could be changed. Conceptual change of this sort is what many postpositivist philosophers of science, such as Kuhn, Toulmin, Laudan, and Shapere, saw as a fundamentally important aspect of science. Thus, the idea that there are conventions at the heart of science was already well developed prior to the Vienna Circle, continued in the work of the Vienna Circle and in Logical Empiricism, and was maintained even in postpositivist philosophy of science. My aim here is to present a coherent picture of conventionalism.

2. Standard Critiques of Conventionalism. Schlick's 1938 interpretation of conventionalism seems to have been extremely influential, in part because of the influence he had on Reichenbach, but also because it was translated by Herbert Feigl and May Brodbeck and reprinted in their influential collection, Readings in the Philosophy of Science (Schlick [1938] 1953). Schlick interpreted Poincaré's conventionalism as a version of holism (i.e., the Duhem-Quine thesis), an epistemological interpretation that has been standard ever since, especially in Popper's critique of conventionalism. Since all empirical theories - not just physical geometry-are underdetermined in the Duhemian sense, the major interpretive problem for those who hold the epistemological interpretation of Poincare's conventionalism is to explain why he holds that only geometry is conventional. Poincaré's conventionalism is limited, so it cannot be equivalent to the Duhem-Quine thesis (or holism). ${ }^{2}$

Schlick's critique of what he calls conventionalism was also very influential, but unfortunately it seems to have muddied the discussion of con-

change some of his views about basic elements of physical theory. While Poincare explicitly denies the existence of atoms in Science and Hypothesis, arguing that the atomic hypothesis was useful but not the only possible explanation for chemical and other phenomena, he accepted their reality after he learned of the work of Jean Perrin (Nye 1976). In at least one case, Poincare also accepted the refutation of a fundamental principle of physics, what he calls a "natural hypothesis," by empirical theory. When he accepted quantum theory as presented in the first Solvay conference in 1911, Poincare gave up the hypothesis of continuity (McCormmach 1967). Even in Carnap's view one can revise by changing languages. While it is true that for Carnap choosing a language includes dividing sentences conclusively between analytic and synthetic for that language, one can start all over with a new language and a different distribution of analytic and synthetic sentences.

2. See especially Poincaré's polemic with LeRoy for a clear statement of the limits of Poincaré's conventionalism (1902, reprinted as 1905 , chapters 10 and 11). 
ventionalism while leaving holism unscathed. Schlick argues that conventionalists are caught in a dilemma (Schlick [1938] 1953, 187): If conventionalism involves only the choice of symbols or of explicitly defined terms, then conventions are analytic. Conventions, taken as changes in explicit definitions, can only result in trivial notational variation, not genuine change of physical theory. If conventions are synthetic, they are testable empirically and Poincaré's metric conventionalism is empirically false. Schlick argues that natural laws must be treated either as genuine claims, in which case they have truth values, are synthetic, and are to be justified or rejected empirically, or they must be treated as explicitly stipulated definitions, in which case they are analytic, lack truth values, and turn out to be irrelevant to science.

Schlick assumes a position here that is clearly equivalent to a strict form of empiricism and therefore begs the question against Kantian or other idealists. Why should a Kantian accept Schlick's view that all synthetic scientific claims must be justified empirically? Even if we accept the view that a priori justifications of knowledge (e.g., by intuition) are problematic and should be ruled out, it does not follow that all knowledge should be justified in the same way. Rather than defend Kant, the point to emphasize here is that Schlick mistakenly treats all empirical statements as having an equal role in the structure of knowledge. What Schlick misses is the element of scientific theories that function as a priori knowledge.

Michael Friedman has detailed how Schlick's influence changed Reichenbach's views on conventionalism after an exchange of letters between the two. As Friedman points out, Reichenbach's important early critique of conventionalism is lost in his later work where he adopts Schlick's interpretation of conventionalism. Reichenbach's early point is that the GTR has shown that metric conventionalism is false:

$[\mathrm{M}]$ athematicians asserted that a geometrical system was established according to conventions and represented an empty schema that did not contain any statements about the physical world. It was chosen on purely formal grounds and might equally well be replaced by a nonEuclidean schema. In the face of these criticisms the objection of the general theory of relativity embodies a completely new idea. This theory asserts simply and clearly that the theorems of Euclidean geometry do not apply to our physical space. (Reichenbach as cited in Friedman 1994, 26, and in Friedman 1999, 66-67)

Although the underlying mathematical structure of GTR does not have a determinate metric, metric is determined empirically in GTR by the distribution of mass and energy. According to the GTR, we do not conventionally choose a metric geometry-Euclidean geometry is not adequate for the GTR. However, this was not widely understood until the 
1970 s and 80 s, that is, until the relatively contemporary discussion of spacetime theories (Friedman 1994, 27, 67). ${ }^{3}$

When Reichenbach adopts Schlick's holistic version of conventionalism in The Philosophy of Space and Time (1958), he argues for conventionalism epistemologically, as can be seen especially clearly in his introduction of his theorem $\Theta(1958,33)$. An empirically testable theory is a combination of geometry and physics, so geometries can be conventionally chosen as long as adjustments are made in physics. Mach makes a similar Duhemian argument against absolute theories of space when he incorporates universal forces in his defense of relationalism. Mach argues that we cannot know whether it is absolute space or distant objects plus a universal force that account for inertial effects (Sklar 1974, 201; Friedman 1983, 296-301).

It will be useful to compare Schlick and Reichenbach's views with more recent literature on spacetime conventionalism, for we will see a parallel debate developed in the critique of Grünbaum's conventionalism. Grünbaum, to his credit, never accepted Schlick's interpretation of Poincaré's conventionalism. He thought that conventionalism follows not from holism but rather solely from the continuity of space. Friedman objected to Grünbaum's argument in Foundations of Space-Time Theories as follows:

If we are to draw any conclusions about "metrical amorphousness" from the continuity of physical space, we need an additional premise: namely, that the only spatio-temporal relations that objectively exist are topological relations and order relations. It follows from this claim that properties and relations not definable in terms of topological properties and order relations do not objectively exist and, consequently, that a continuous space objectively lacks metrical properties. (Friedman 1983, 304)

To shorten a long story considerably, it is now widely acknowledged that metric conventionalism requires a fully relational theory of space, yet none of the historically accepted space or spacetime theories-Newtonian, STR or GTR - have been fully relational in the required sense. Friedman's point here is essentially the same as Reichenbach's point in 1920, that GTR shows metric conventionalism to be untrue. Thus, the major critique of geometric conventionalism that was developed within the recent literature

3. I should mention, however, that I have recently found a similar idea from F. Enriques, always a critic of Poincaré's conventionalism, who writes in 1938 about "Poincaré's celebrated doctrine of conventions that we had the occasion to examine and refute in our book Problems of Science (1906). The development of Einstein's theory of relativity has given the coup de grâce to this doctrine" (Enriques 1938, 29). 
on space and time argued that physical theory does not support the conventionalist thesis. Sklar would seem to agree with this point when he argues that the only possible way to defend metric conventionalism now is with holism (Sklar 1986). While Schlick and Popper's critique of conventionalism was philosophical, the recent critique was based on natural science.

The recent discussion has shown that with the proper background theory, Poincaré's conventionalism would have been possible. It is a merely contingent fact (and rather surprising too) that uniform acceleration is detectable and unrelativizable, while uniform velocity is not detectable and is relativisable. The most important point for this discussion, however, is that the epistemological status of the metric of space or spacetime changed as we changed background theories. In this case, Newtonian theory and GTR each set the epistemological status of space (or spacetime). In Newtonian theory we know a priori that space is Euclidean, but in GTR, the metric is determined empirically. Thus, background theory and context determine what is a priori and what is empirical, that is, which parts of the theory function as a priori knowledge. For example, the Newtonian theories of space and of motion are empirical theories, but the metric of space is Euclidean and functions as a priori knowledge within Newtonian theory. It is true that an empirical theory determines the metric of space, but only in a very indirect and abstract sense. The metric of space is not testable within any of the historical spacetime theories. Perhaps our current theory of the metric of spacetime received an empirical confirmation, along with the rest of the GTR, but this metric was neither conceived of nor justified by empirical considerations in anything like the way that ordinary empirical claims are.

This viewpoint is, of course, close to Carnap's in that the background commitments of a scientific theory determine what is a priori and what is empirical. However, Carnap makes a mistake in considering the background commitments as a language. He sees a priori truths as analytic, leaving himself vulnerable to Schlick's critique of conventions as trivial, as well as to further critiques by Quine. The process of determining what is a priori and what is empirical is embedded within a physical, empirical theory. It is necessary to develop a considerable amount of theory before empirical tests are possible at all, and even then, it may seem that empirical tests have very little to do with, for example, the truth of Euclidean geometry. Nevertheless, Newtonian theory is ultimately empirical, that is, our change from Newtonian theory to STR and to GTR has an empirical basis.

\section{Geometric Conventionalism and the Constitution of Knowledge.}

Reichenbach introduces his famous distinction between two meanings of 
'a priori' in the following passage from The Theory Relativity and A Priori Knowledge:

Kant's concept of a priori has two different meanings. First, it means "necessarily true" or "true for all times" and secondly, "constituting the concept of object." The second meaning must be clarified. According to Kant, the object of knowledge, the thing of appearance, is not immediately given. Perceptions do not give the object, only the material of which it is constructed. Such constructions are achieved by an act of judgment. The judgment is the synthesis constructing the object from the manifold of the perception. (Reichenbach 1965, 48)

Constitution needs to be clarified because it could seem to lead immediately to idealism - the construction of physical objects by perception. For example, we might consider that when Kuhn introduces his "changes of world view" language in The Structure of Scientific Revolutions, he says, "I have so far argued only that paradigms are constitutive of science. Now I wish to display a sense in which they are constitutive of nature as well" (Kuhn [1962] 1997, 110). Here conventionalists seem to be caught in a further dilemma. If there are synthetic a priori principles, then it seems that one is committed to idealism, since the a priori element in knowledge constitutes the object of knowledge. If, on the other hand, all synthetic statements are a posteriori, then one is committed to empiricism and Schlick's dilemma appears. However, Quine's critique of the analytic-synthetic distinction should give one pause when considering Schlick's dilemma. It may be true that conventionalism is difficult to formulate without the analytic-synthetic distinction, but Schlick's critique is difficult to formulate as well. While the empiricist version of conventionalism seems problematic, I believe that it can be defended and is preferable to idealism. ${ }^{4}$

Fortunately, idealism is not required to defend conventions as functionally a priori; all that is necessary is to recognize the different epistemological status of various parts of a physical theory. All of these parts can be ultimately empirical, but they are not all empirical in the same way, since some are more embedded and less directly testable than others are. C. I. Lewis emphasizes this crucial point in his discussion of how his view differs from that of the Vienna Circle (Lewis [1941] 1970, 106). Even more significantly, some elements of a theory are required before others can be tested or indeed even formulated. By paying attention to what is required for testing, the theory itself tells us what is functionally a priori

4. Friedman $(1997,2001)$ and De Pierris (1992) highlight the Kantian constitutive function of a priori knowledge. I agree with considering the a priori as a necessary precondition in a Kantian sense, but reject the idealistic overtones of the term constitution. I am also happy to embrace the naturalism and empiricism that they reject. 
and what is empirical. Friedman has recently elaborated several examples of a priori elements in physical science (2001, esp. ch. 2) and there is a longstanding literature on the status of Newton's laws that shows that they cannot all be empirical at the same time (e.g., Pap 1946). Although their intent is anticonventionalist, Forster and Sober's defense of the evidential significance of simplicity as a criterion is congenial with the position that I adopt here (1994). By analyzing Akaike's statistical methods that are widely employed in science, they discover that

the data tell you more than you may have thought. ... At least in the context of the curve-fitting problem, Akaike's technical result provides a benchmark that identifies the degree to which simplicity has evidential significance. (Forster and Sober 1994, 27)

However, Forster and Sober do not deny that application of Akaike's theorem requires the use of both physical and (pure) mathematical assumptions. In this sense, a functional a priori remains, and will always remain, even if we discover that we have more of an empirical basis than most had thought when we choose a simpler theory. The ultimate status of some of the fundamental assumptions required to apply Akaike's theorem is ambiguous in a way that supports my claim that classification of scientific principles as a priori or empirical is a pragmatic decision, not a permanent grounding of science:

[T] he assumption that measurement errors are normally distributed around a mean value is so widespread in science that it is often referred to as the law of errors. On the theoretical side, the central limit theorem affords a theoretical explanation of these empirical facts. In a somewhat humorous tone, Cramér $(1946,232)$ sums up by quoting Lippman as saying: 'everyone believes in the law of errors, the experimenters because they think it is a mathematical theorem, the mathematicians because they think it is an experimental fact,' and adds that 'both parties are perfectly right, provided that their belief is not too absolute.' (Forster and Sober 1994, 30)

What we have here is a set of regularity assumptions that come in stronger and weaker mathematical forms. Although the assumptions are consistent with experimental statistical work, they cannot be claimed to have been tested. They are rather assumptions that are required for purely mathematical reasons.

The issue between idealist and empiricist versions of conventionalism seems to come down to whether a priori principles are taken to be analytic or synthetic. Carnap's work represents the fullest working out of the view that a priori principles are analytic, which leaves him open to the criticisms that Quine makes in "Two Dogmas of Empiricism" (1953) and in "Truth 
by Convention" (1935). Idealist leaning arguments seem to use the notion of constitution in order to distinguish the functionally a priori from the rest of knowledge. For example, according to Reichenbach, it is the constitutive function that gives principles of physics and parts of mathematics their distinctive epistemological status, one that is not captured by strict empiricism and that is masked by holism:

$[\mathrm{T}]$ his view is distinct from an empiricist philosophy that believes it can characterize all scientific statements indifferently by the notion "derived from experience." Such an empiricist philosophy has not noticed the great difference existing between specific physical laws and the principles of coordination and is not aware of the fact that the latter have a completely different status from the former for the logical construction of knowledge. The doctrine of the a priori has been transformed into the theory that the logical construction of knowledge is determined by a special class of principles, and that this logical function singles out this class, the significance of which has nothing to do with the manner of its discovery and the duration of its validity. (Reichenbach 1965 as cited in Friedman 1994, 23, and in Friedman 1999, 62)

Empiricists can explain how it is possible to "harden" any empirical statement, that is, to hold it fixed as a postulate, but this may not be enough of a distinction to overcome holism. Quine is comfortable admitting that in practice, some statements are easy to harden and difficult to test, while others are easy to test and difficult to harden. However, for the functional account of the a priori to be compelling, it is not clear that the division between the a priori and empirical parts of knowledge has to be as hard and fast as the distinction between analytic and synthetic sentences, or as the distinction between constitutive and nonconstitutive elements of knowledge.

First, how the distinction is to be drawn seems less important than showing that there must be some functionally a priori element in order to proceed. If there is always an a priori element of knowledge at least in a functional sense, then there is no need to know in advance what counts as a priori and what does not. When theories are tested or even formulated, many explicit and implicit assumptions are made. It is possible to go back over an experiment and challenge any of these assumptions as long as one is willing to develop an alternative. The functional account of the a priori does not require some aspects of knowledge to be permanently untestable, rather, only that some aspects of theory be accepted conditionally. Second, emphasizing the functional a priori aspect of parts of scientific theories and ignoring the distinction between analytic and synthetic statements avoids the necessity of developing a theory of language or of meaning. Empirical theory determines what is a priori and what is not. Since no theory of 
meaning and language will be needed, Quine's arguments against Carnap will not apply. Furthermore, Quine's main argument in "Two Dogmas of Empiricism," that there is no way to explain or justify the analyticsynthetic distinction without begging the question, is simply irrelevant because we are not trying to ground or to justify science. Beyond the usual pragmatic and conceptual arguments, there is no need to justify conventional choices with a philosophical theory-something Quine, as a pragmatist, should know well! As Wittgenstein said, "The difficulty is to realize the groundlessness of our believing" $(1969,24)$.

4. Positioning. By embracing empiricism, we can put to rest the epistemological debate between rationalism and empiricism. However, if we wish to understand the nature of science, rather than continue the pretension that we are putting it on a firm foundation, Quinean holism gives us practically no answers, while conventionalism provides a framework for significant contributions to our understanding of scientific knowledge. Since I adopt naturalism, fallibilism, and empiricism, it may seem that I have simply landed with both feet in Quine's camp, and in a sense that is true. The naturalism that I can accept I define negatively as the view that there is no "first philosophy" that is prior to and independent of science. By fallibilism I mean that there are no unrevisable beliefs and no certainty, and by empiricism I mean that all truths, save explicitly stipulated definitions, are empirically justified, though the functionally a priori parts of physical theory are only empirical in the extremely tenuous sense that the general theory that classified them as a priori is an empirical theory.

An interesting extension of Quine's view can be found in Michael Resnik's work on the philosophy of mathematics (Resnik 1997). ${ }^{5}$ Presenting a defense of empiricism and a reduced and subtle kind of realism in mathematics, Resnik defends the indispensability thesis and promotes Quinean holism, arguing that mathematics is not separable from the rest of science and that justification of mathematics, once we move away from local justifications within various branches of mathematics, ultimately involves the role that mathematics plays in science as a whole. Resnik defends epistemic holism by arguing that the objects of physics are not so different from those in mathematics and by accounting for the stability of mathematics pragmatically. Mathematics will be tinkered with less fre-

5. Resnik's main new additions to discussions in the philosophy of mathematics are structuralism to account for the incompleteness of mathematical objects and a disquotational account of reference and truth. Of particular significance is the point that an immanent account of reference eliminates one of the strongest arguments against mathematical realism. A transcendental approach seems to require a causal theory of reference, and since mathematical objects are causally inert, it seems impossible to be a transcendent realist in mathematics. 
quently than experimental hypotheses and becomes relatively a priori, that is, more likely to be taken for granted. However, Resnik admits that mathematics is never falsified $(1997,133)$, leading one to wonder whether this is not in itself prima facie evidence for a fundamental epistemic difference between mathematics and the rest of science. This difference may not be apparent when one's only concern is the ultimate justification of mathematics, but it is immediately apparent when one considers the very different roles that mathematics and physical theory play in the web of knowledge (to use Quine's term). Thus, in a sense, the difference between Quinean holism and a theory of the functional a priori is a matter of emphasis. Quineans emphasize the (ultimately) empirical nature of mathematical knowledge, while functional a priorists emphasize the conventional basis of scientific knowledge. This does not mean, however, that the ultimate grounding of science is a priori. Science as a whole remains empirical, but saying so tells us very little about science. By simply granting that such grounding is empirical, we can set aside the issue of the ultimate justification of mathematics and other fundamental principles of science and focus attention instead on how these elements of scientific theories function as a priori knowledge and as conventions, which is a much more significant result concerning the structure of science.

\section{REFERENCES}

Coffa, J. Alberto (1991), The Semantic Tradition from Kant to Carnap: To the Vienna Station. Cambridge: Cambridge University Press.

Cramér, H. (1946), Mathematical Methods of Statistics. Princeton: Princeton University Press.

Creath, Richard (1991), “Every Dogma Has Its Day”, Erkenntnis 35: 347-389.

De Pierris, Graciela (1992), "The Constitutive A Priori", in Philip Hanson and Bruce Hunter (eds.), Return of the A Priori. Calgary: University of Calgary Press, 179-214.

Enriques, Federigo (1906), Problemi di scienza. Bologna: Zanichelli.

- (1938), La théorie de la connaissance scientifique de Kant à nos jours. Paris: Hermann.

Forster, Malcolm, and Elliott Sober (1994), "How to Tell when Simpler, More Unified, or Less 'Ad Hoc' Theories Will Provide More Accurate Predictions", British Journal for the Philosophy of Science 45 (1): 1-35.

Friedman, Michael (1983), Foundations of Space-Time Theories: Relativistic Physics and Philosophy of Science. Princeton: Princeton University Press.

(1994), "Geometry, Convention, and the Relativized A Priori", in Wesley Salmon and Gereon Wolters (eds.), Logic, Language, and the Structure of Scientific Theories. Pittsburgh: University of Pittsburgh Press, 21 -34. Reprinted in Friedman 1999, 59-70. - (1997), "Helmholtz's Zeichentheorie and Schlick's Allgemeine Erkenntnislehre: Early Logical Empiricism and Its Nineteenth-Century Background", Philosophical Topics 25 (2): 19-50.

(1999), Reconsidering Logical Positivism. Cambridge: Cambridge University Press. (2001), Dynamics of Reason. Stanford, CA: CSLI Publications.

Hacking, Ian (1992), "Style' for Historians and Philosophers", Studies in History and Philosophy of Science 23: 1-20.

Hanson, Philip, and Bruce Hunter, (eds.) (1992), Return of the A Priori: Canadian Journal of Philosophy Supplementary Volume 18. Calgary: University of Calgary Press. 
Kuhn, Thomas S. ([1962] 1997), The Structure of Scientific Revolutions. Chicago: University of Chicago Press.

(1990), "Dubbing and Redubbing: The Vulnerability of Rigid Designation", Scientific Theories 14: $298-318$.

Lakatos, Imre ([1970] 1978), "Falsification and the Methodology of Scientific Research Programs", in J. Worrall and G. Currie (eds.), Philosophical Papers: The Methodology of Scientific Research Programmes. Cambridge: Cambridge University Press.

Lewis, Clarence Irving ([1941] 1970), "Logical Positivism and Pragmatism", in John D. Goheen and John L. Jr. Mothershead (eds.), Collected Papers of Clarence Irving Lewis. Stanford: Stanford University Press, 92-112.

McCormmach, Russell (1967), "Henri Poincaré and the Quantum Theory", Isis 58: 37-55.

Neurath, Otto ([1929] 1974), "Wissenschaftliche Weltauffassung: Der Wiener Kreis", in Marie Neurath and Robert S. Cohen (eds.), Empiricism and Sociology. Dordrecht: Reidel.

Nye, Mary Jo (1976), “The Nineteenth-Century Atomic Debates and the Dilemma of an 'Indifferent Hypothesis'", Studies in History and Philosophy of Science 7: 245-268.

Pap, Arthur (1946), The A Priori in Physical Theory. New York: King's Crown Press.

Poincaré, Henri (1902), "Sur la valeur objective de la science", Revue de métaphysique et de morale 10: $263-293$. (1905), La valeur de la science. Paris: Flammarion, 1970.

Quine, Willard Van Orman ([1935] 1976), "Truth by Convention", The Ways of Paradox and Other Essays. Cambridge: Harvard University Press, 77-106.

([1953] 1980), "Two Dogmas of Empiricism", From a Logical Point of View. Cambridge: Harvard University Press, 20-46.

Reichenbach, Hans (1958), Philosophy of Space and Time. New York: Dover. - (1965), The Theory of Relativity and A Priori Knowledge. Berkeley: University of California Press.

Resnik, Michael D. (1997), Mathematics as a Science of Patterns. Oxford: Oxford University Press.

Richardson, Alan (1997), “Two Dogmas about Logical Empiricism: Carnap and Quine on Logic, Epistemology, and Empiricism”, Philosophical Topics 25 (2): 145-168.

Schlick, Moritz ([1938] 1953), “Are Natural Laws Conventions?", in Herbert Feigl and May Brodbeck (eds.), Readings in the Philosophy of Science. New York: Appleton Century Crofts, $181-188$.

Sklar, Lawrence (1974), Space, Time, and Spacetime. Berkeley: University of California Press.

_ (1986), Philosophy and Spacetime Physics. Berkeley: University of California Press.

Stein, Howard (1992), "Was Carnap Entirely Wrong, After All?", Synthese 93: 275-295.

Wittgenstein, Ludwig, (1969), On Certainty. Oxford: Basil Blackwell. 
Copyright of Philosophy of Science is the property of Philosophy of Science Association and its content may not be copied or emailed to multiple sites or posted to a listserv without the copyright holder's express written permission. However, users may print, download, or email articles for individual use. 